Case Report

\title{
Cutaneous and Gastrointestinal Symptoms in Two Patients with Systemic Mastocytosis Successfully Treated with Omalizumab
}

\author{
Sofie Lieberoth and Simon Francis Thomsen \\ Department of Dermatology, Bispebjerg Hospital, 2400 Copenhagen NV, Denmark \\ Correspondence should be addressed to Simon Francis Thomsen; simonfrancisthomsen@gmail.com
}

Received 1 October 2014; Revised 6 January 2015; Accepted 7 January 2015

Academic Editor: Larry W. Moreland

Copyright (C) 2015 S. Lieberoth and S. F. Thomsen. This is an open access article distributed under the Creative Commons Attribution License, which permits unrestricted use, distribution, and reproduction in any medium, provided the original work is properly cited.

\begin{abstract}
The pathogenesis of mastocytosis is not well defined and thus treatment remains challenging and remains on a palliative basis. We present two cases (a 48-year-old woman and a 57-year-old man) with indolent systemic mastocytosis in whom omalizumab (antiIgE) reduced gastrointestinal and cutaneous symptoms significantly. This observation provides additional insight into the effects of omalizumab on systemic mastocytosis.
\end{abstract}

\section{Introduction}

Mastocytosis refers to a group of myeloproliferative disorders characterized by excessive proliferation and accumulation of mast cells in tissues. Whereas cutaneous mastocytosis (CM) is limited to the skin, systemic mastocytosis (SM) describes forms of mastocytosis in extracutaneous organs, with or without skin involvement. The majority of SM patients present with a point mutation in the KIT gene at the 816 position. Systemic mastocytosis comprises clinical variants ranging from indolent systemic mastocytosis to mast cell leukaemia and is commonly associated with anaphylaxis and symptoms including palpitations, flushing, cutaneous itch, nausea, and diarrhoea. The WHO diagnostic major criterion for SM includes multifocal, dense aggregates of mast cells (15 or more) detected in sections of bone marrow and confirmed by tryptase immunohistochemistry or other special stains, whereas minor criteria are as follows: (a) in biopsy section, more than $25 \%$ of the mast cells in the infiltrate have atypical morphology, or, of all the mast cells in the aspirate smear, more than 25\% are immature or atypical; (b) mast cells coexpress CD117 with CD2 and/or CD25; (c) detection of KIT point mutation at codon 816 in bone marrow, blood, or other extracutaneous organs; (d) serum total tryptase persistently $>20 \mathrm{ng} / \mathrm{mL}$ (not a valid criterion in cases of systemic mastocytosis with associated clonal hematologic non-mast-cell lineage disease). A diagnosis of SM may be rendered if one major plus one minor criterion or three minor criteria are fulfilled [1]. The pathogenesis of mastocytosis is not well defined and thus treatment remains challenging and on a palliative basis $[2,3]$.

Omalizumab is a humanized murine monoclonal antibody that conjugates free serum IgE and reduces binding to the high-affinity IgE receptor (FCeRI) on mast cells and basophils, thereby stabilizing and reducing the potential reactivity of these cells [4]. Omalizumab has been used successfully in and is approved for the treatment of disorders in which mast cells are pathogenetically involved such as allergic asthma [5] and chronic urticaria [6]. Therefore, therapy with this antibody in mastocytosis seems worth considering. We present two cases of indolent SM which showed good response to omalizumab treatment.

\section{Case Presentation}

The first patient was a 48-year-old woman with CM for the last 15 years and with diagnosed SM for one year but with diffuse systemic symptoms for the last five years. She also had psoriasis and was formerly diagnosed with cutaneous malignant melanoma and dysplasia of the cervix. SM was verified by one major criterion and three minor WHO criteria: presence of multifocal, dense aggregates of mast cells in 
TABLE 1: Studies of mastocytosis treated with omalizumab.

\begin{tabular}{|c|c|c|c|}
\hline Study & Patients $(n)$ & Dose & Effect \\
\hline \multicolumn{4}{|l|}{ Systemic mastocytosis } \\
\hline Carter et al., 2007 [7] & 2 & $300 \mathrm{mg} / 4$ weeks & $\begin{array}{l}\text { Patient I: no further anaphylactic episodes } \\
\text { Patient II: reduced gastrointestinal and anaphylactic episodes }\end{array}$ \\
\hline Pitt et al., $2010[8]$ & 1 & $300 \mathrm{mg} / 4$ weeks & No further anaphylactic episodes \\
\hline Kontou-Fili et al., 2010 [9] & 1 & $300 \mathrm{mg} / 4$ weeks & No further anaphylactic episodes \\
\hline Douglass et al., 2010 [10] & 1 & $150 \mathrm{mg} / 4$ weeks & No further anaphylactic episodes or cardiac arrest \\
\hline Paraskevopoulos et al., 2013 [11] & 1 & $300 \mathrm{mg} / 4$ weeks & No further anaphylactic episodes \\
\hline Kibsgaard et al., 2014 [12] & 1 & $300 \mathrm{mg} / 4$ weeks & No further anaphylactic episodes \\
\hline \multicolumn{4}{|l|}{ Cutaneous mastocytosis } \\
\hline Siebenhaar et al., 2007 [13] & 1 & $150 \mathrm{mg} / 4$ weeks & Reduced cutaneous symptoms \\
\hline Matito et al., 2013 [14] & 1 & $450 \mathrm{mg} / 4$ weeks & Reduced cutaneous symptoms \\
\hline Sokol et al., 2014 [15] & 1 & $375 \mathrm{mg} / 2$ weeks & Reduced cutaneous symptoms \\
\hline
\end{tabular}

bone marrow confirmed by tryptase immunohistochemistry (major criterion) and expression of CD2, CD25, and CD117 in bone marrow, persistently elevated serum tryptase (up to $86 \mu \mathrm{g} / \mathrm{L}$ ), and KIT D $816 \mathrm{~B}$ mutation in duodenal and bone marrow biopsies (minor criteria). The patient experienced severe cutaneous itch with widespread rash typical of CM, diarrhoea, palpitations, episodes of musculoskeletal pain, and fatigue daily or almost daily. She was previously treated with oral nonsedating $\mathrm{Hl}$-antihistamines at high dose (fexofenadine $180 \mathrm{mg}$ up to four times daily) for six months with reduced occurrence of skin symptoms but not of gastrointestinal or musculoskeletal symptoms. Injections with omalizumab (300 mg s.c. once every four weeks) were initiated, and, within a few months, she experienced resolution of gastrointestinal and cutaneous symptoms, whereas musculoskeletal pain remained. She was followed up for eleven months and continued having a good response of omalizumab. She experienced no side effects of the treatment.

The second patient was a 57-year-old man with CM for the last 30 years and with diagnosed SM for three years. He was otherwise healthy but was on permanent disability pension due to symptoms of mastocytosis. SM was verified by one major criterion and two minor WHO criteria: presence of multifocal, dense aggregates of mast cells in bone marrow confirmed by tryptase immunohistochemistry and with expression of CD117 but not CD2 (major criterion) and persistently elevated serum tryptase $(>200 \mu \mathrm{g} / \mathrm{L})$ and KIT D816B mutation (minor criteria). The patient experienced diarrhoea (loose stools up to five times daily) and severe daily cutaneous itch and widespread cutaneous mastocytosis. He was treated unsuccessfully with PUVA (three times per week) plus high dose of nonsedating H1-antihistamines (ceterizine/levocetirizine $5-10 \mathrm{mg}$ up to three times daily) for two months and, hereafter, with UVA-1 (three times per week) plus high dose of nonsedating H1-antihistamines (ceterizine/levocetirizine 5-10 mg up to three times daily) and montelukast for one year and four months. He was subsequently switched to a strong topical corticosteroid (used two times per day) for one month with no effect. Finally, omalizumab treatment (300 mg s.c. once every four weeks) was initiated but paused for six months after only one injection, as he was unable to attend scheduled ambulatory visits due to a motor vehicle accident and a fractured leg. Treatment with omalizumab was resumed and, after three months, he experienced marked reduction in cutaneous itching as well as resolution of gastrointestinal symptoms. He was followed up for 15 months on omalizumab and continued having a good response with no side effects of the treatment.

\section{Discussion}

Omalizumab inhibits the binding of IgE to the surface of mast cells and basophils by forming complexes with free IgE in serum. This results in downregulation of FCeRI expression on mast cells and basophils and reduction of mast cell and basophil activation [4]. The mechanisms whereby omalizumab decreases symptoms in patients with mastocytosis are not well known. Also, little is known about the pathogenesis of symptoms in mastocytosis patients. Yet, it is plausible that the reduction in mast cell activity caused by omalizumab may reduce these symptoms caused by an excessive number of mast cells.

There are several case reports suggesting that omalizumab may decrease symptoms of mastocytosis, both in its systemic and cutaneous form. To our knowledge, six previous studies with a total of seven patients have reported successful treatment of SM with omalizumab [7-12]. These studies of SM all reported less anaphylactic episodes, with the exception of one patient in whom fewer gastrointestinal symptoms were reported. Another three studies totalling three patients have reported successful treatment of CM with omalizumab [13-15]. These reports all found reduction in skin symptoms (Table 1). In line with our patients, previous studies reported very few side effects of omalizumab, the only exception being Jandus et al. [16] who describe a patient with SM and Hymenoptera venom allergy who was administered omalizumab as add-on therapy to improve venom immunotherapy tolerability and who-during omalizumab treatment-developed sleep disturbances.

We did not taper the omalizumab dose or change the dosing intervals during treatment nor did we monitor IgE 
or other serological markers among our patients. It is possible that symptom resolution in SM can be obtained with lower doses of omalizumab (e.g., $150 \mathrm{mg}$ ) and longer dosing intervals (e.g., every four to eight weeks). Also, it is possible that our patients would have benefitted symptomatically from treatment with oral cromolyn. However, we did not use this drug.

Our report of reduced gastrointestinal and cutaneous symptoms in two patients with SM treated with omalizumab expands on previous findings providing additional insight into the effects of omalizumab for SM.

\section{Conflict of Interests}

The authors declare that there is no conflict of interests regarding the publication of this paper.

\section{References}

[1] H. P. Horny, D. D. Metcalfe, J. M. Bennet et al., Eds., WHO Classification of Tumours of Haematopoietic and Lymphoid Tissues, IARC Press, Lyon, France, 4th edition, 2008.

[2] J. Robyn and D. D. Metcalfe, "Systemic mastocytosis," Advances in Immunology, vol. 89, pp. 169-243, 2006.

[3] P. Valent, "Diagnostic evaluation and classification of mastocytosis," Immunology and Allergy Clinics of North America, vol. 26, no. 3, pp. 515-534, 2006.

[4] P. Vichyanond, "Omalizumab in allergic diseases, a recent review," Asian Pacific Journal of Allergy and Immunology, vol. 29, no. 3, pp. 209-219, 2011.

[5] G. D’Amato, A. Salzillo, A. Piccolo, M. D’Amato, and G. Liccardi, "A review of anti-IgE monoclonal antibody (omalizumab) as add on therapy for severe allergic (IgE-mediated) asthma," Therapeutics and Clinical Risk Management, vol. 3, no. 4, pp. 613619, 2007.

[6] I. Ivyanskiy, C. Sand, and S. F. Thomsen, "Omalizumab for chronic urticaria: a case series and overview of the literature," Case Reports in Dermatology, vol. 4, no. 1, pp. 19-26, 2012.

[7] M. C. Carter, J. A. Robyn, P. B. Bressler, J. C. Walker, G. G. Shapiro, and D. D. Metcalfe, "Omalizumab for the treatment of unprovoked anaphylaxis in patients with systemic mastocytosis," Journal of Allergy and Clinical Immunology, vol. 119, no. 6, pp. 1550-1551, 2007.

[8] T. J. Pitt, N. Cisneros, C. Kalicinsky, and A. B. Becker, "Successful treatment of idiopathic anaphylaxis in an adolescent," The Journal of Allergy and Clinical Immunology, vol. 126, no. 2, pp. 415-416, 2010.

[9] K. Kontou-Fili, C. I. Filis, C. Voulgari, and P. G. Panayiotidis, "Omalizumab monotherapy for bee sting and unprovoked 'anaphylaxis' in a patient with systemic mastocytosis and undetectable specific IgE," Annals of Allergy, Asthma and Immunology, vol. 104, no. 6, pp. 537-539, 2010.

[10] J. A. Douglass, K. Carroll, A. Voskamp, P. Bourke, A. Wei, and R. E. O'Hehir, "Omalizumab is effective in treating systemic mastocytosis in a nonatopic patient," Allergy: European Journal of Allergy and Clinical Immunology, vol. 65, no. 7, pp. 926-927, 2010.

[11] G. Paraskevopoulos, E. Sifnaios, K. Christodoulopoulos, F. Mantopoulou, M. Papakonstantis, and D. Sabaziotis, "Successful treatment of mastocytic anaphylactic episodes with reduction of skin mast cells after anti-IgE therapy," European Annals of Allergy and Clinical Immunology, vol. 45, no. 2, pp. 52-55, 2013.

[12] L. Kibsgaard, T. Skjold, M. Deleuran, and C. Vestergaard, "Omalizumab induced remission of idiopathic anaphylaxis in a patient suffering from indolent systemic mastocytosis," Acta Dermato-Venereologica, vol. 94, no. 3, pp. 363-364, 2014.

[13] F. Siebenhaar, W. Kühn, T. Zuberbier, and M. Maurer, "Successful treatment of cutaneous mastocytosis and Ménière disease with anti-IgE therapy," Journal of Allergy and Clinical Immunology, vol. 120, no. 1, pp. 213-215, 2007.

[14] A. Matito, C. Blázquez-Goñi, J. M. Morgado et al., "Shortterm omalizumab treatment in an adolescent with cutaneous mastocytosis," Annals of Allergy, Asthma and Immunology, vol. 111, no. 5, pp. 425-426, 2013.

[15] K. C. Sokol, A. Ghazi, B. C. Kelly, and J. A. Grant, “Omalizumab as a desensitizing agent and treatment in mastocytosis: a review of the literature and case report," The Journal of Allergy and Clinical Immunology: In Practice, vol. 2, no. 3, pp. 266-270, 2014.

[16] P. Jandus, O. Hausmann, G. Haeberli, T. Gentinetta, U. Mueller, and A. Helbling, "Unpredicted adverse reaction to omalizumab," Journal of Investigational Allergology and Clinical Immunology, vol. 21, no. 7, pp. 563-566, 2011. 


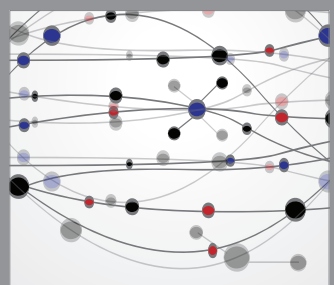

The Scientific World Journal
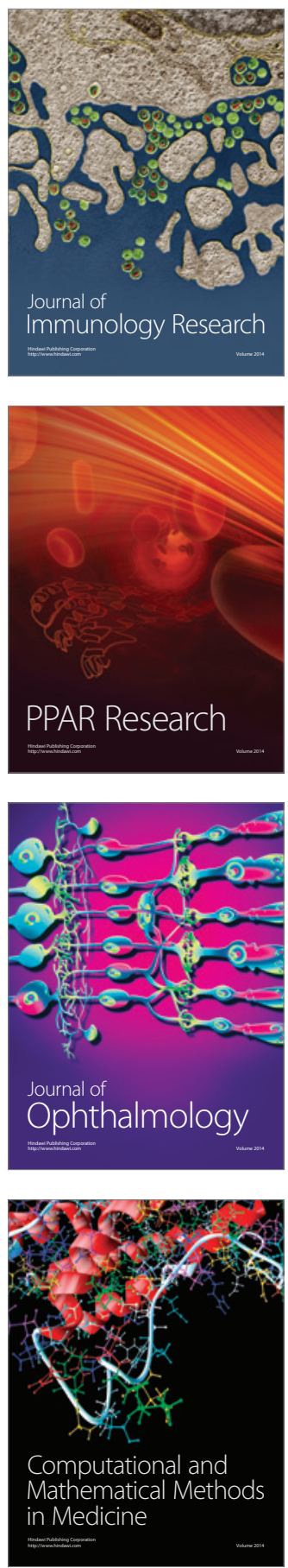

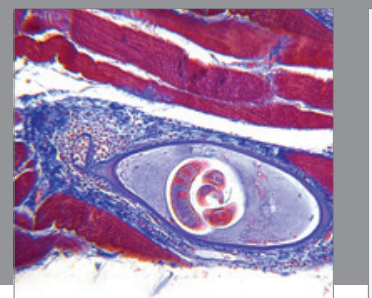

Gastroenterology

Research and Practice
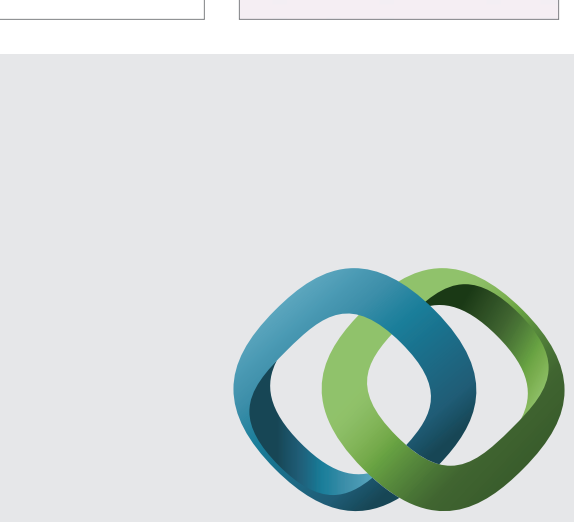

\section{Hindawi}

Submit your manuscripts at

http://www.hindawi.com
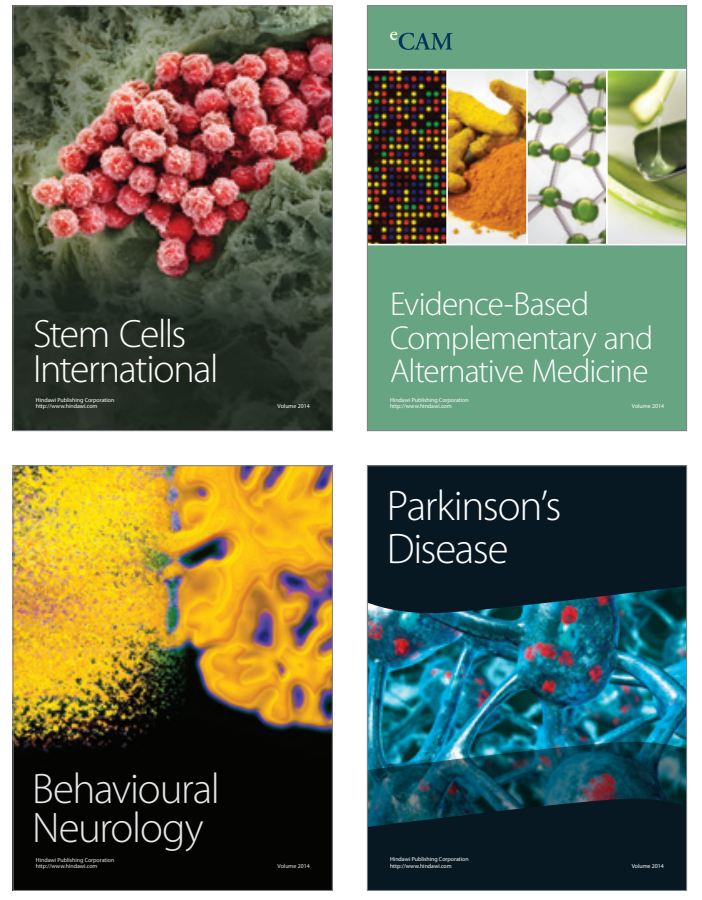
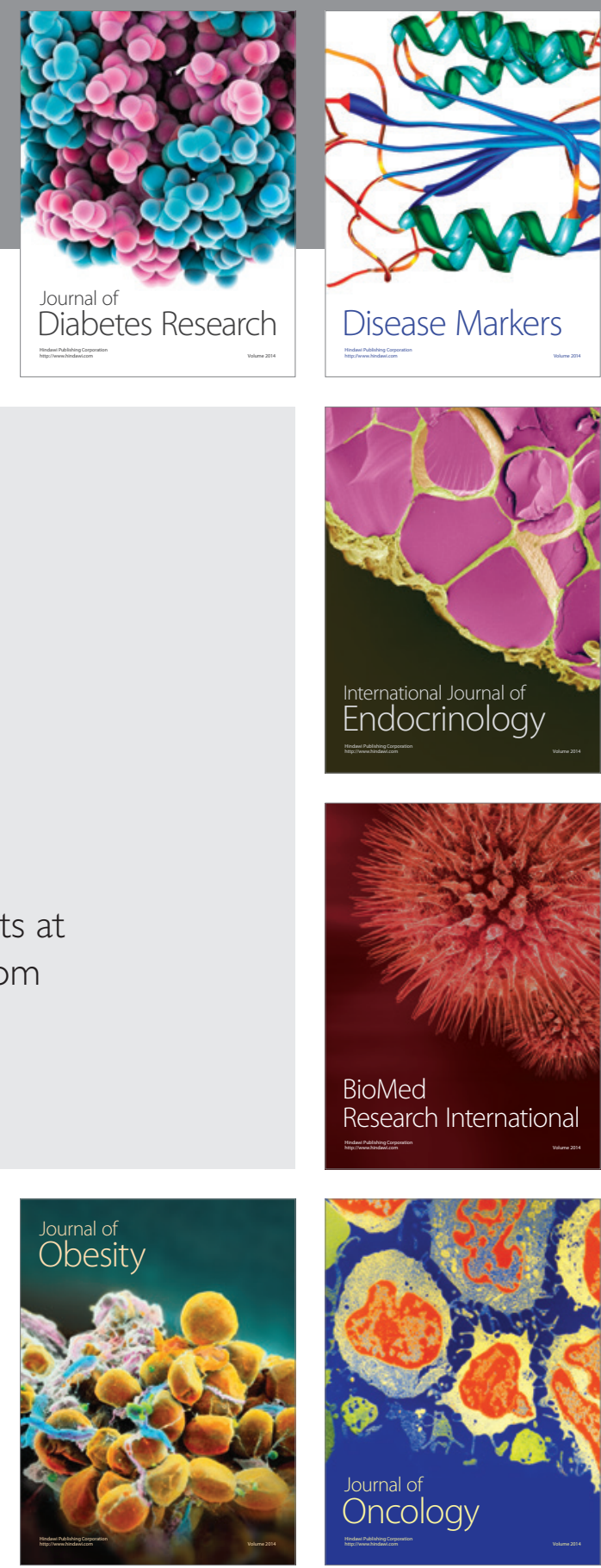

Disease Markers
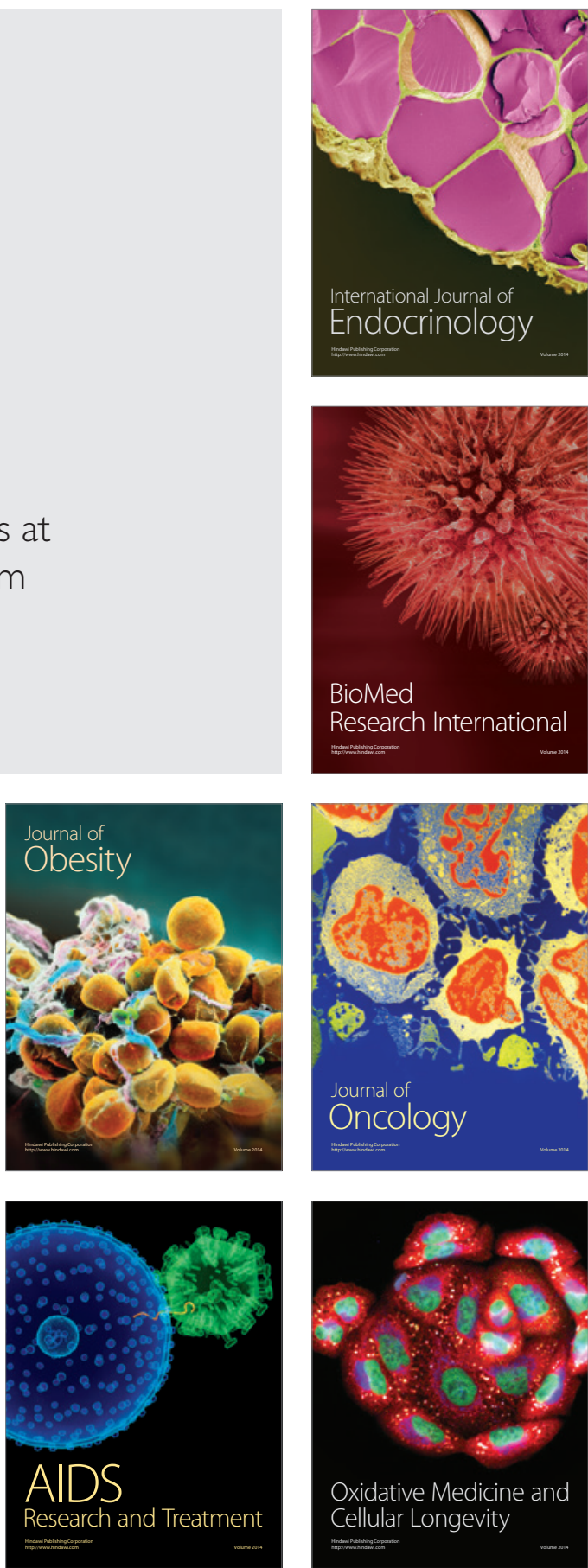